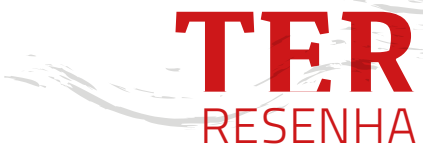

\title{
EXPERIÊNCIA MAIS QUE HUMANA COM OUTRO FOGO
}

FAGUNDES, Guilherme Moura. 2017. Outro fogo.

Brasília, Brasil, cor, $21 \mathrm{~min}$

\section{FELIPE FIGUEIREDO}

ORCID

Universidade Federal de São Paulo, Guarulhos, SP, Brasil

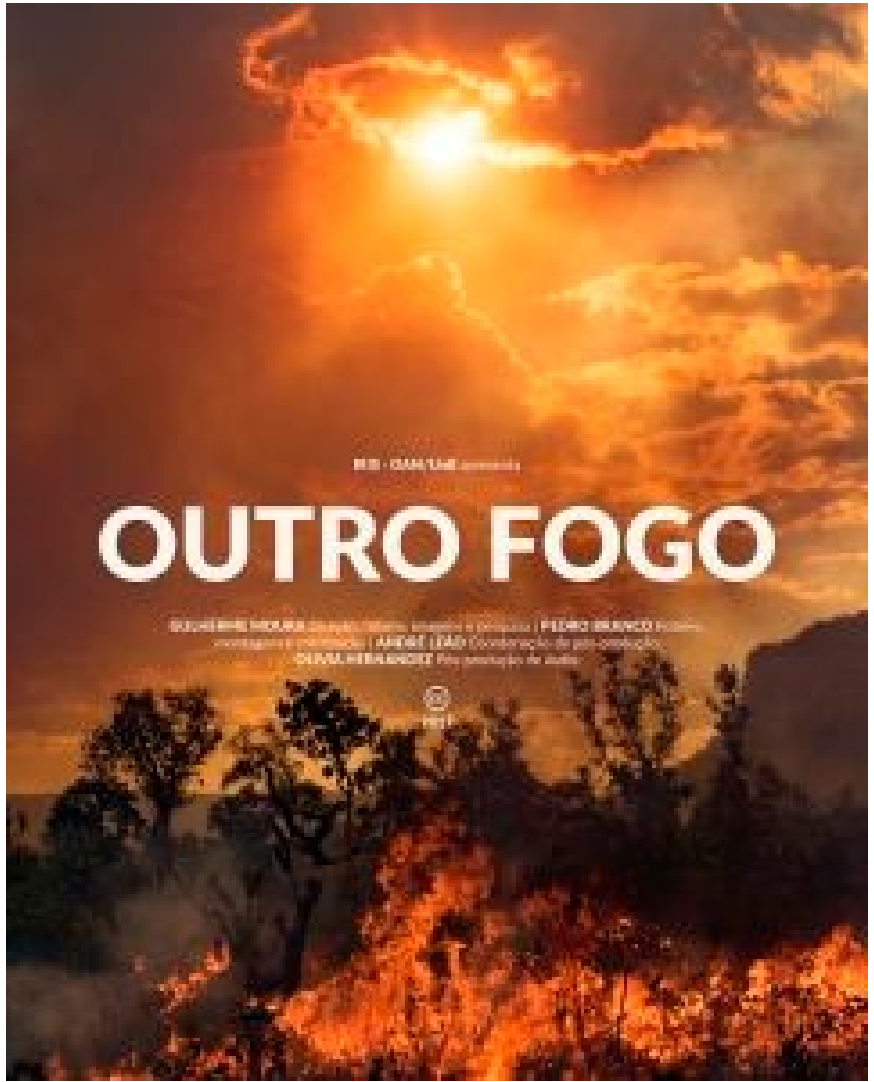


O que é o medo? Este questionamento abre o filme Outro fogo (2017), dirigido por Guilherme Moura Fagundes, ${ }^{1}$ vencedor do primeiro lugar do Prêmio Pierre Verger / XII Edição Filme Etnográfico, em 2018. Os mundos criados pelo filme nos levam a repensar as relações possíveis com 0 meio ambiente. Somos confrontados com sentimentos de angústia em relação às práticas socioambientais que nos são apresentadas. o que vemos em Outro fogo são literalmente maneiras de habitar e manejar o ambiente que, pelo menos do contexto do Sudeste urbano do qual escrevo, pensamos ser relações de destruição em relação à paisagem. Nesta resenha, portanto, parto de uma perspectiva situada das possíveis experiências sensoriais que podem suscitar diferentes interpretações do filme, desde a experiência do autor enquanto espectador privilegiado (Triana e Gómez 2016).

Somos transportados a um ambiente em chamas. Ao som de assobios e estalos, somos levados na primeira parte do filme a confrontar a questão do medo e dos supostos perigos do fogo. o que surge na tela é um instrumento que pinga fogo na mata, deixando um rastro de chamas ao longo do trajeto da caminhonete que leva a pessoa que manuseia a ferramenta, junto do cinegrafista. Enquanto os assobios criam uma atmosfera soturna, percebemos que se trata de estalos do fogo em contato com a mata. O som continua ao exibir planos tomados pela mata do Cerrado, toda amarelada sob a luz do sol incandescente. $O$ fogo nestes planos é um elemento central: um é produto da ação humana, outro é aquele que queima o ambiente pelo sol.

O estalo do fogo prossegue até a imagem de uma fogueira que assa algumas carnes em gravetos. Dessa vez é o fogo que alimenta os homens que trabalham de brigadistas para o Instituto Chico Mendes de Conservação da Biodiversidade (ICMBio), como podemos notar em seus uniformes. Somos então situados em Jalapão e na Chapada dos Veadeiros, no verão de 2016, locais de relações socioambientais entre brigadistas e fogo, mas não apenas isso. 0 filme nos leva para um cerrado queimado, mas cheio de vida, desde a mata até os animais que ali habitam. Ao nos confrontarmos com o filme, não apenas somos transportados a um mundo de imagens e sons, mas de verdadeiras experiências físicas, que escapam a uma narrativa inteiramente racional (Jameson 1995).

Um dos pontos altos da narrativa é a verdadeira relação corporal que os brigadistas têm com as chamas. Batem no fogo de maneira tão intensa e numa sincronia tão perfeita que parece uma cena ensaiada. Alguns planos dividem muito bem as cinzas queimadas de um lado e a mata do

1. Não é intenção da resenha discutir questões de autoria, mas cabe ressaltar que além do diretor há outras pessoas e instituições na produção do filme, inclusive aqueles que participam como personagens. 
Cerrado, separadas pelo fogo, fazendo conviver chamas e mata, fogo e Cerrado e, no meio de ambos, o brigadista como elemento fundamental da relação entre os dois, criando ele mesmo certa proximidade e intimidade com o fogo. Destaco não apenas a dificuldade da atividade do brigadista tão próximo das chamas, mas também do cinegrafista, que se colocou corporalmente próximo delas, criando, a partir da narrativa fílmica, um confronto direto dos efeitos audiovisuais com a experiência corporal do espectador. As imagens das chamas são intensas, chegam a cobrir todo o plano junto da fumaça. Trazem uma sensação de proximidade e o questionamento de Riobaldo do início do filme, do medo que é produzido dentro da gente, que às vezes sacoleja, sobretudo a partir do momento que os brigadistas avistam mais um foco das chamas e correm até ele, quando a trilha sonora insurge por entre as queimadas.

Podemos chegar a torcer pelos brigadistas no suposto combate às chamas. Seguindo o sentido da narrativa do filme, somos confrontados com a seguinte questão: qual a procedência deste fogo? Fogo feito pela ação humana? Fogo criminoso como aquele que assola a Amazônia nos últimos tempos? Fogo proveniente do sol? Que experiência sensível o filme nos provoca? Sentimentos "pirofóbicos" podem invadir o espectador no que considero ser o ponto de maior tensão do filme, quando até a trilha sonora converge com os movimentos dos brigadistas para/com as chamas.

No entanto, a partir da segunda metade do filme, irrompe uma experiência ambígua em relação ao fogo. Surge na noite uma conversa de personagens que não enxergamos. Falam sobre o medo, sobre esta pirofobia que nos acomete nas cenas anteriores. Ela também é compartilhada por alguns brigadistas, provavelmente por aqueles menos experientes. Para quem é esta fala? Podemos, enquanto espectadores, tomá-la para nós, "se a carapuça servir", como dizem. Aliás, o medo é este "produzido dentro da gente", este "depositado" - retomando mais uma vez a fala de Riobaldo da epígrafe -, e a vida é onde este "sarro de medo" se destrói. No caso, a vida e experiência dos manejadores de fogo que, numa relação de verdadeira pirofilia, utilizam as queimadas com finalidades conservacionistas e agropastoris. Como comenta Fagundes (2016, 60), "O MIF [manejo integrado do fogo], como se convencionou chamar no Jalapão, consiste em uma perspectiva ambiental presente em diversas savanas pelo mundo. Como o nome sugere, visa ‘integrar' saberes e práticas científicas e locais relacionadas ao fogo (...)”.

Após o diálogo, surge na tela a ferramenta de pingar fogo, mais uma vez em cima da caminhonete. Agora fica explícito que são agentes do ICMBio que a utilizam. Provavelmente os mesmos que também tentavam controlar o fogo. Mais sentimentos ambíguos surgem dessa sequência, até que percebemos a maneira como os agentes se relacionam com o 
ambiente e com o vento para poder soltar o fogo. Um fogo que "devém ferramenta” (Fagundes 2016) para criar verdadeiras formas socioambientais de relação que, como nas palavras de um dos personagens, "não vai matar o Cerrado" e à qual todos os entes não humanos que ali habitam vão poder agradecer. Assim, manejo do fogo adaptado à região do Cerrado pode beneficiar as espécies que ali habitam e substituir o paradigma de combate aos incêndios.

A própria forma narrativa do filme coloca os dois paradigmas em questão e como eles afetam o imaginário das relações com o fogo no Cerrado. Enquanto na primeira parte nos confrontamos com a pirofobia, com cenas intensas de contenção do fogo por parte dos brigadistas, a segunda metade se concentra em agenciar uma narrativa audiovisual acerca do manejo, desvelando as relações estabelecidas com entes humanos e não humanos através do fogo e do discurso. Há uma atenuação da tensão posta pelo filme acerca da questão do medo do fogo para uma relação de "philia" com ele.

Assim, a narrativa fílmica em Outro fogo joga com sentimentos ambíguos em relação ao fogo por meio da dicotomia (fobia e philia) colocada e ao mesmo tempo questionada por ela. Este medo "depositado" e que reflete de dentro da gente pode ser confrontado com as práticas regionais de manejo do fogo no Jalapão, como dito na conversa que ouvimos na metade do filme, para sairmos "com outra mentalidade". Ao conceber o cinema como máquina mimética, "ou seja, como narrador moderno capaz de nos provocar e transmitir conhecimentos que afetam sensivelmente o espectador" (Triana e Gómez 2016, 118), e considerar que tal máquina provoca experiências sensíveis e reflexões éticas, Outro fogo nos direciona para experienciar e refletir diferentes concepções de relações multiespécies, mas também relações sociotécnicas cuja ferramenta central é o fogo, podendo refletir os limites do "outro", frequentemente construído dentro das perspectivas antropológicas, para além dos limites do humano, para uma experiência outra que humana ou mais que humana.

É outro porque desestabiliza o que imaginamos (pelo menos no contexto urbano do Sudeste do qual escrevo) que seja o agenciamento do fogo na mata, ao trazer as experiências de relação dos manejadores com aquele ambiente. É outro porque não é aquele fogo feito recentemente na Amazônia para o agronegócio. É outro fogo porque se faz outro em seu devir-ferramenta nas relações socioambientais no Cerrado. 0 filme, fruto de pesquisa científica em antropologia social, nos proporciona além de tudo um sentimento de alteridade radical para/com este elemento não humano, que invade os planos e chega a tocar quem assiste. 


\section{REFERÊNCIAS BIBLIOGRÁFICAS}

Fagundes, Guilherme Moura. 2016. Como o fogo devém ferramenta? Notas sobre manejo e manipulação no cerrado (Jalapão-TO). Novos Debates: Fórum de Debates em Antropologia, vol. 2, no. 2: 59-67.

Jameson, Fredric. 1995. As marcas do visivel. Rio de Janeiro: Graal.

Rosa, João Guimarães. 1986. Grande sertão: veredas. Rio de Janeiro: Nova Fronteira.

Triana, Bruna e Diana Gómez. 2016. A análise fílmica na antropologia: tópicos de uma proposta teórico-metodológica. In A experiência da imagem na etnografia, ed. Andrea Barbosa, Edgar Teodoro da Cunha, Rose Satiko Gitirana Hikiji e Sylvia Caiuby Novaes, 109-126. São Paulo: Terceiro Nome.

MATERIAL AUDIOVISUAL

Fagundes, Guilherme Moura. 2017. Outro fogo. Brasília, Brasil, cor, 21', formato digital. Disponivel em: <https://vimeo.com/313635468>. Acesso em: 10 out. 2019.

FELIPE FIGUEIREDO é mestrando em Ciências Sociais na Universidade Federal de São Paulo (Unifesp) e membro do Grupo de Pesquisas Visuais e Urbanas (Visurb). E-mail: felipe.figueiredo@unifesp.com

Licença de uso. Este artigo está licenciado sob a Licença Creative Commons CC-BY. Com essa licença você pode compartilhar, adaptar, criar para qualquer fim, desde que atribua a autoria da obra. 